\title{
Organizational issues for the lean success in China: exploring a change strategy for lean success
}

Tian Gao ${ }^{1,2^{*}}$ (D) and Bruce Gurd ${ }^{3}$

\begin{abstract}
Background: The purpose of this paper is to explore a change strategy for lean success in hospitals based on a comprehensive review of the Chinese literature.

Methods: The methodology is a systematic review of the Chinese literature which identified 212 case study papers about lean implementation. We did a thematic content analysis of the 212 papers.

Results: Lean applications in Chinese hospitals show significant increases and are mainly used in the fields of outpatient services, operating rooms, pharmacy and logistics. Most hospitals applied lean as a single project but some were beginning to use lean as a systemic path for improvement with an emphasis on lean and strategy. The main goals were to increase the operating efficiency and reduce operating costs. Patients were not central to lean applications. Chinese hospitals appear to lack a full understanding of lean. Four factors appear to be critical for lean success - organizational leadership, adequate technology, stakeholder involvement and individual and organizational benefits. The relationship of these factors changes over time.
\end{abstract}

Conclusions: This is the first paper to provide a comprehensive view of lean application in Chinese hospitals. The findings presented in this paper provide a systemic evidence to the application of lean in healthcare.

Keywords: Lean application, Healthcare, Chinese hospital, Systematic review

\section{Background}

Lean, also known as lean thinking, and the Toyota Production System, is a process reengineering philosophy developed to successful practice by Toyota and consisting of a set of strategic guiding principles and operational tools $[1-3]$.

An important concept in lean is to divide activities into added value and non-value-added value. Value-added activities are considered activities that satisfy a customer's demand for a product or service; all other activities are non-value-added. By using lean tools, such as value stream maps, organizations can identify activities and bottlenecks that have no added value and provide standardized solutions to these problems. Lean management can create an organization that can accomplish more and better tasks

\footnotetext{
* Correspondence: gaoty001@mymail.unisa.edu.au

${ }^{1}$ Planning and Finance Department, Jinan Central Hospital Affiliated with Shandong University, Jinan 250013, China

${ }^{2}$ University of South Australia, Adelaide, Australia

Full list of author information is available at the end of the article
}

with less time, less human support, less cost, less space, less trauma and fewer mistakes [4]. Originating in manufacturing industry; hospitals have become important sites for lean applications as the result of the need for performance improvement. Lean is considered a solution to meet the efficiency and productivity needs of improving the quality of health services [3]. From the initial application of lean thinking in hospitals to the present, there have been more than 10 years of history [5], and it has been adopted rapidly in health care settings with the goal of supporting the development of a better, value-based organization [6-8]. Many studies claim that applying lean has achieved good results in improving hospital performance $[9,10]$. The barriers to lean implementation have led to a slower adoption of lean in hospitals [6]. Organizational issues surrounding the successful implementation of innovation are critical, but there has been insufficient research attention [2].

(c) The Author(s). 2019 Open Access This article is distributed under the terms of the Creative Commons Attribution 4.0 International License (http://creativecommons.org/licenses/by/4.0/), which permits unrestricted use, distribution, and 
Since the middle 1990's, as China's medical reform has deepened, hospitals have been facing increased pressure to improve medical quality and operational efficiency. In this context, some Chinese hospitals have used lean to improve their performance.

This paper explores organizational issues for the lean success in healthcare through a review of the application of lean in Chinese hospitals based on a systematic survey of the existing literature. The next section provides a review of the literature on lean, introduces the Cresswell and Sheikh model [11] of organizational factors, and introduces the context of Chinese hospitals.

\section{Lean}

Prior studies show the positive outcomes of the application of lean in healthcare, such as improving quality of care, safety, increasing patient and staff satisfaction, achieving productivity and cost efficiency, and better financial outcomes $[12,13]$. Some problems in lean practices have been identified. Inconsistent with the origins of Lean in Japan, it has not employed as a systematic approach, a philosophy, and mainly used as a technical fix of practices [14] without a supportive culture for facilitating the lean implementation [15].

While there is a significant literature, systematic evidence of the application of lean is limited [16-19], and further research is needed. There is very limited research done on the application of lean in healthcare in China $[16,20,21]$.

\section{Organizational issues for successful lean implementation} Compared with other industries, the healthcare industry is much more complex, lean concepts have not penetrated all its aspects in hospitals [22]. Many studies have explored factors for the successful implementation of lean, such as the support of each level of management [23], organizational leadership [24], technical support from external agencies [25], internal consultants' support [16], creating cultural change [24], fostering a long-term view of continuous improvement [14, 22], emphasizing the benefits of the project to the organization, such as patient safety, patient satisfaction, and the hospital's business and economic performance [14]. Organizational readiness is considered a prerequisite for the initiation and subsequent implementation of lean projects [12]. Successful implementation of lean requires attention to factors including a strong leadership team for lean support, training and stakeholder involvement [22, 25], the basic stability of the organization [26], connecting lean with strategy and establishing a measurement and reward system linked to lean goals [22].

Figure 1 presents a model adapted from Cresswell and Sheikh [11] which connects the factors that affect the successful implementation of a technology innovation including social factors, technical factors and organizational factors; we have extended this to a managerial innovation such as lean. We extend the idea of "adequate technology" to the spread of lean tools available to the hospital. Not only are these factors related but the relationship changes at different points of the implementation. The exact relationship between these dimensions is not clear and further work is needed in this field [11, 27].

\section{The Chinese hospital context}

With the expanding coverage of China's medical insurance over the last ten years, China's hospitals are facing increasing pressure because of limited growth in medical resources but, at the same times, a growth in patient outcomes. From 2005 to 2015, the number of outpatients and inpatients in China have increased 121 and 193\% respectively [28] whereas resources have increased at a much lower pace with the hospital buildings only increasing by $75 \%$, beds by $108 \%$, and staff by $65 \%$.

During this growth the Chinese government has been continuing to attempt reform to ensure that hospitals provide better services at reasonable prices including the 2005 Ministry of Health 'Administration Year' [29]. In 2009, the Chinese cabinet passed a new health care reform plan which increased competition with a reduction of profit from pharmaceuticals, increased patient choice and growth of medical insurance to at least $90 \%$ of the entire Chinese population by 2011 [30, 31]. Medical insurance has become the major source of hospital revenues in China [32].

The use of payment methods of medical insurance payments, such as fee-for-services and total budgets has forced the hospitals to reduce their costs and improve their productivity. According to the hospital reform policy [33], before the end of 2015 Medical insurance payment reform will cover all public hospitals, covering more than $30 \%$ of the hospital discharges of public hospitals at a county level. By 2017, China will fully implement a compound payment method of which DRGs (diagnosis-related disease groups) will be the main method, capitation and per diem payments will be supplementary. The medical insurance department will be paid according to the type of disease. For a disease type, no matter what kind of medical items happen, the one-time payment will be made according to the price of the disease type. If the medical cost exceeds the payment price of the disease, the medical institution will have to bear the cost of exceeding the payment price.

These all point to the need for Chinese hospitals to effectively control unreasonable cost increases, strengthen medical quality management, further improve medical efficiency and decrease medical costs. 


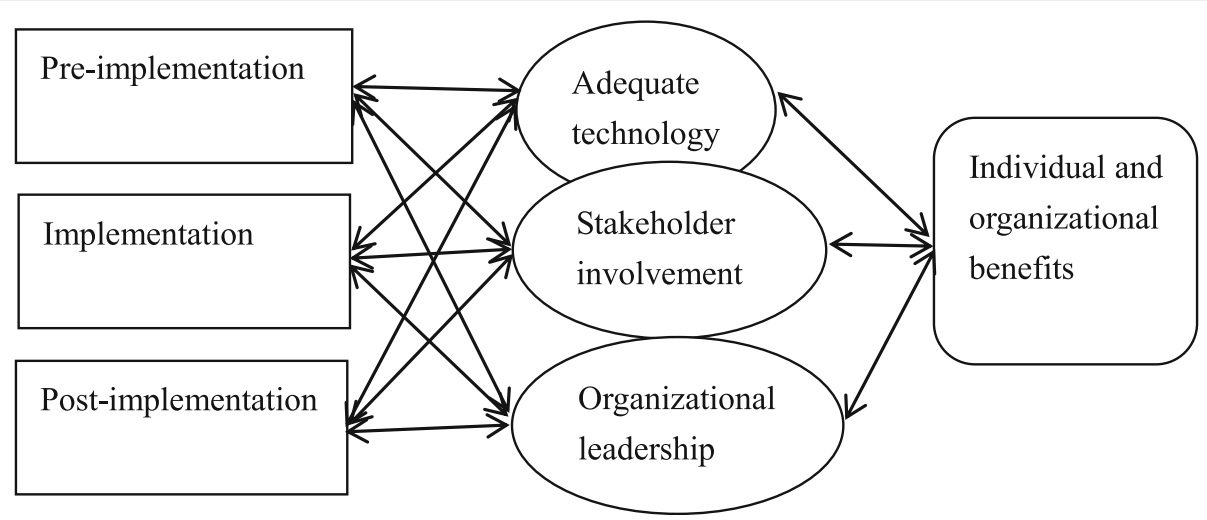

Fig. 1 The interaction of technological, social and organizational factors in hospital information technology innovation over time (adapted from Cresswell, K. and A. Sheikh, Organizational issues in the implementation and adoption of health information technology innovations: An interpretative review. International Journal of Medical Informatics. 2013; 82(5): 73-86)

There has been a very important policy change since the health care reform in the mid-1980s, in that the Chinese Government tightened the fiscal budgets for public hospitals and other health care institutions $[34,35]$. The government only finances part of the operating outlay of public hospitals and the subsidy from the government for public hospitals was cut to $14-30 \%$ of total hospital spending, which is only basic personnel salaries and new capital investments [36, 37]. The public hospitals were given more economic autonomy to find new financial resources and generate more capital and profits from other services and pharmaceuticals to cover the gap between their total spending and the government's financial subsidy $[31,38,39]$. In this environment innovations in health delivery are likely, and lean management is attractive for this focus on improving operations performance as well as drivers of cost effectiveness.

The first research question is, what is the current state of the lean implementation in Chinese hospitals?The focus is on the trend, approaches, outcomes and problems of the application of Lean in Chinese hospitals. Furthermore, for exploring the successful lean implementation, our second research question is, what are the relations between technological, social and organizational dimensions at different phases of implementation?

\section{Methods}

This study used quantitative methods including print media indicators (PMI) and content analysis. We analyzed PMI following Braam et al.'s [40] approach in the study of Netherlands. The resources surveyed were Google Scholar, Baidu scholar, and three Chinese academic data bases - Wanfang Data, CQVIPVIP (Chongqing VIP Information Co., Ltd.) database and CNKI (Chinese National Knowledge Infrastructure) database to find published refereed journal papers using key words related to lean in Chinese hospitals before 2017. 379 journal papers were found, with 212 case studies of implementations and 167 theoretical papers arguing for the virtues of lean and exploring issues in its use. Around 127 hospitals had claimed they had implemented lean and introduced their experiences. 20 hospitals have published more than one article which provides relatively more comprehensive data on the application of lean.

Through the use of thematic content analysis, we refined the data from the 212 papers of case studies of lean implementations around the trend, approaches, the understanding of lean, lean tools used in practice, outcomes and problems. Then we coded, classified and the data in an Excel spreadsheet for further analysis.

\section{Results}

\section{Social aspects}

\section{The trend of papers published on lean}

Figure 2 indicates the growth of the published papers on lean in Chinese hospitals. After the first paper reported the lean practice in Chinese hospitals was published in 1997, the second paper appeared eight years later. In 2008, papers were published at a more rapid rate than in 2007. The year 2009 can be seen as a milestone of the diffusion of lean in Chinese hospitals. In 2011, there was a jump in both the total number of papers and the number of papers related to the lean practice. In 2012, 2014, and 2015 the trend kept rising. The data represents a rapid rise of the diffusion and implementation of lean in Chinese hospitals.

\section{The patterns of lean implementation}

Most of the 127 hospitals that have used lean have more than 500 beds (see Fig. 3), the biggest one has 4398 beds. Most of them (125) are public hospitals. Of the 127 hospitals, 6 hospitals gained external consultants' help to implement lean. They published 48 articles of lean 


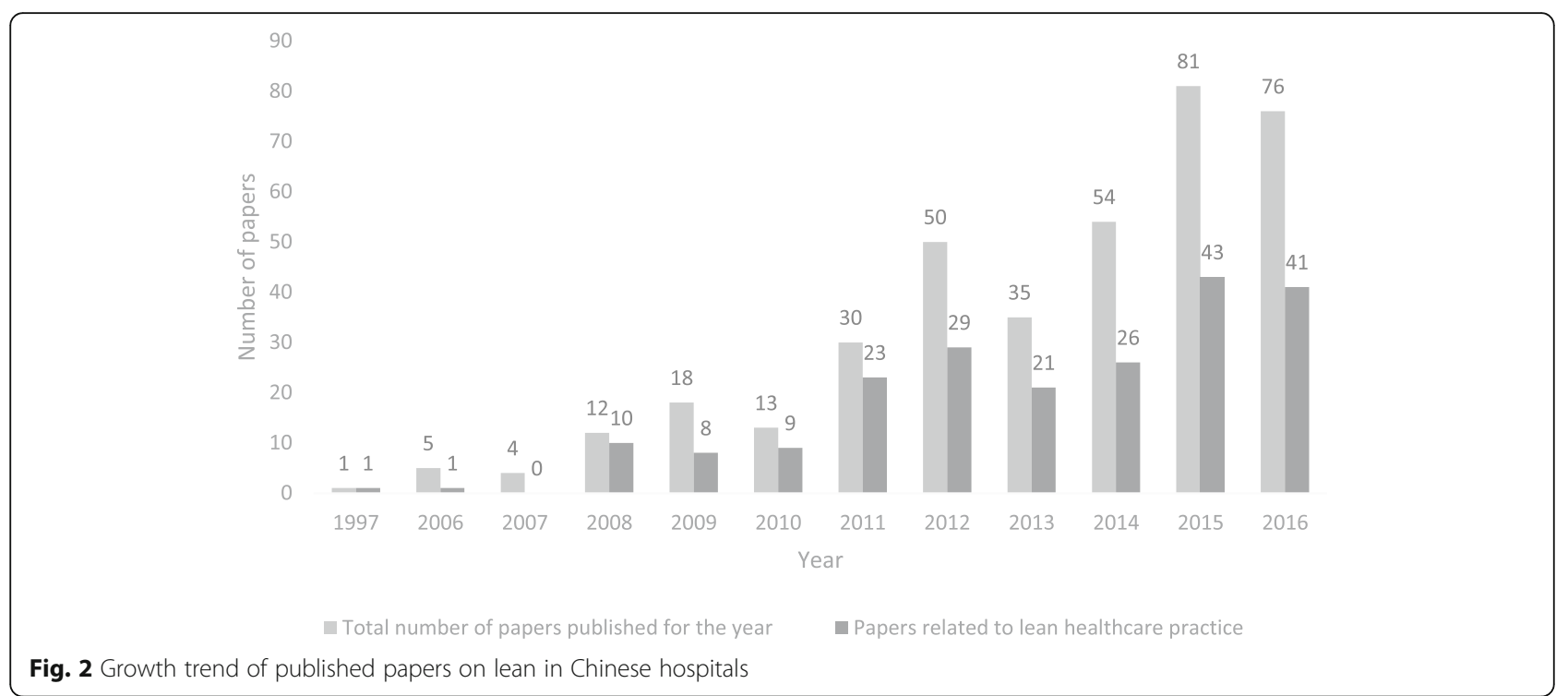

application which occupied $23 \%$ of the total lean practice articles.

Fifty one provided the information at the time they started to use lean (see Fig. 4). The first reported user of lean in Chinese hospitals is a workers hospital of the biggest automobile manufacturing group in China, so it is not surprising that they learned to use the Toyota production system in 1994 [41]. Most hospitals started to use lean between 2008 and 2015. To summarize, excluding 2015, at least 69 hospitals have had more than two years of experiences using lean.

\section{Technical issues}

Most of the hospital (115 hospitals) recognized lean as process optimization tools which can eliminate waste. Eighty five looked at lean as continuous improvement and a very small group saw it as a strategy and a philosophy. Some papers only used the word "lean" in the title, but showed no particular understanding of lean [42]; it seems that lean is anything. Much traditional work, putting on the coat of lean, has become a lean improvement. Hence, what lean is needs to be clarified in Chinese hospitals.

\section{Hospital fields in which lean has been implemented}

Only seven hospitals claimed to have applied lean across the whole hospital [41, 43-47] but not always covering all staff. In one case a hospital had implemented lean for 3 years, but it had not spread to all staff [45].

Specifically, lean was most widely used in pharmacy and operation room (28 hospitals) [48, 49], and then outpatient process optimization (22 hospitals) [50, etc.],

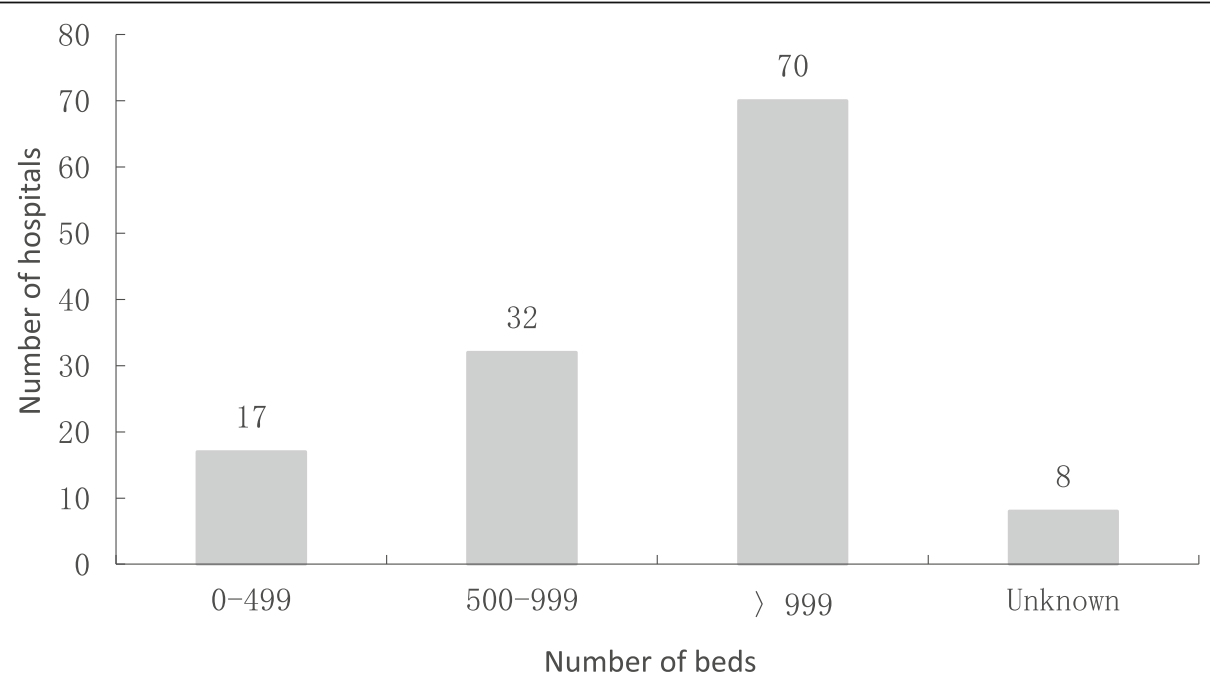

Fig. 3 Hospital size 


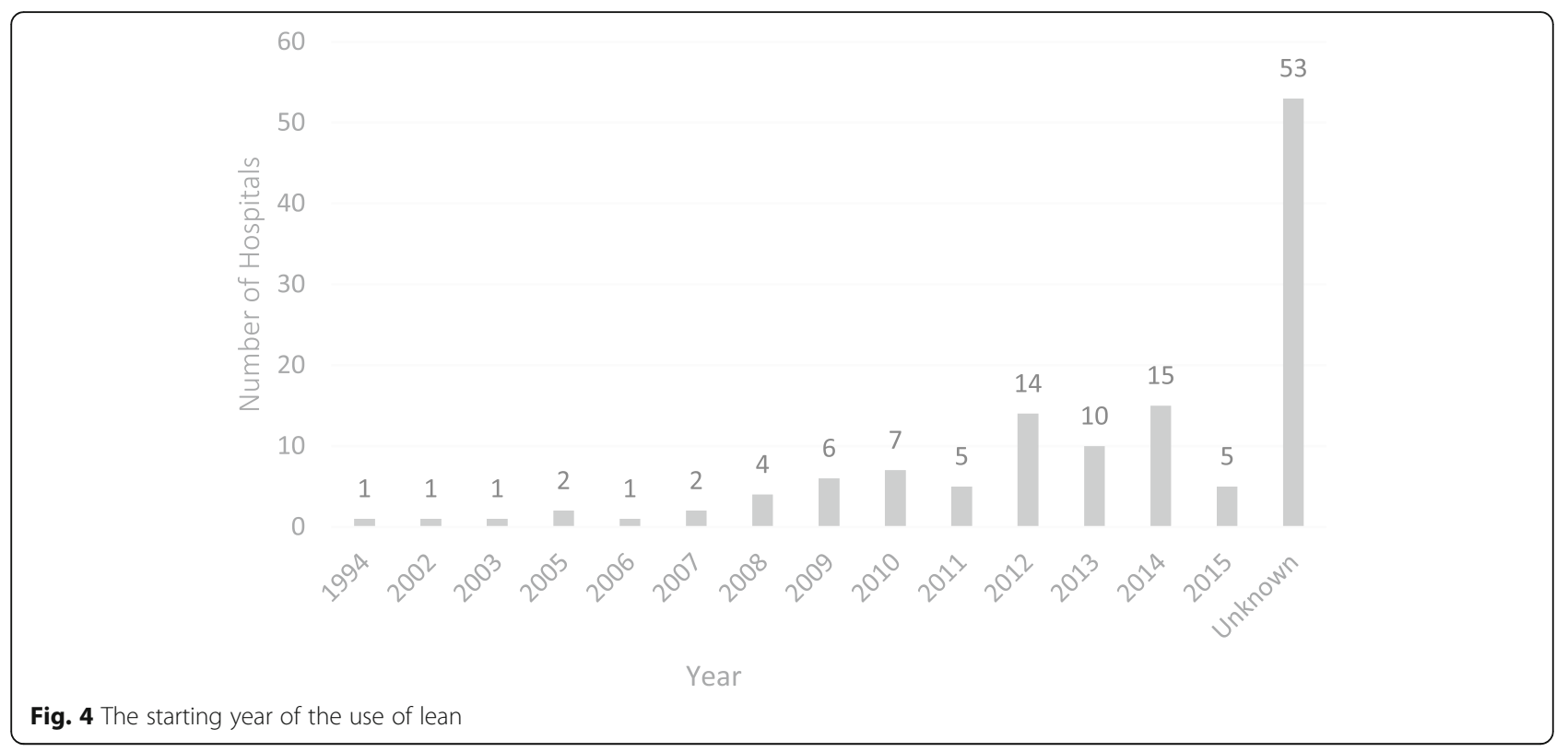

outpatient service and nursing management (14 hospitals respectively) [51]. It was also used in the field of integrated management, for example, financial management [52], human resource management [53] and hospital culture Change [54] (see Table 1). Compared with hospitals in Western countries, there are two distinct differences. The first is that pharmacy plays an important role in hospital operations and it also an important part of the services for the patients. Second, China's hospitals usually have a large number of outpatients. For example, Changhai Hospital of Second Military Medical University has around 11,000 outpatient visits per day [50], and in Guangdong Province the Traditional Chinese Medical Hospital the number of outpatient pharmacy prescriptions is 800012,000 per day in 2009 [55]. So it is not surprising that the procedure optimization related to pharmacy and outpatient services are the most areas using lean in Chinese hospitals.

\section{The main lean tools used in Chinese hospitals}

In the lean practice of 127 hospitals, 39 lean tools are mentioned (See Table 2). Among the 39 tools, 17 were used by only one hospital. 5S (sort, set in order, shine, standardize and sustain) (and related $6 \mathrm{~s}$ (sort, set in order, shine, standardize sustain and safety) and $8 \mathrm{~s}$ (sort, set in order, shine, standardize, sustain,safety,save and study)) is the most widely used tool (31 hospitals), then Value Stream Map (24 hospitals) and Fishbone Diagram (24 hospitals) (See Table 2).

The top three are the tools for site management, waste elimination and quality improvement. The two hospitals with the most lean tools, using 15 and 13 tools respectively, are Taihe Hospital and Nanfang Hospital which are supported by external consultants. This indicates that the lean management knowledge and technology in the Chinese hospitals needs to be popularized. The most frequently used top ten lean tools are process improvement and the improvement of the physical area. This is consistent with the characteristics of the Chinese hospitals in 4.3.

\section{Organizational factors}

\section{The approaches to the application of lean}

In addition to the eight hospitals which applied lean across the whole hospital ${ }^{1}$ the other 119 hospitals only used lean in some units. Most of them implemented lean as a project. Around $80 \%$ of hospitals chose to do pilots first, and then gradually promoted lean practice across the whole hospital.

It is argued that the selection of lean projects mainly depends on whether the project itself can meet the relevant characteristics and conditions: first, the cycle of the project is short and can yield faster results; second, less resource will be involved in the project, its process is relatively independent; third, the project can have a large impact and play a benchmark role; fourth, the project manager is passionate, staff agree with the project [44].

These points reflect the difficulties in the implementation of lean. That is, lean implementation is a long-term process, needs a certain time to display the effect, often needs to cross the department to implement, needs to master certain knowledge, requires to get everybody involved and needs a supportive culture.

\section{The outcomes of the application of lean}

In this study, nearly all of the hospitals provided information regarding the outcomes of the application of 
Table 1 Hospital fields in which lean has been implemented

\begin{tabular}{|c|c|c|c|}
\hline Hospital units & № & Supportive management & № \\
\hline Pharmacy & 28 & Nursing management & 14 \\
\hline Operating Room & 22 & Logistic material supply & 12 \\
\hline Outpatient service & 14 & Specialty not specified & 8 \\
\hline Clinical Laboratory & 6 & File management & 6 \\
\hline Specialty not specified & 6 & Equipment management & 6 \\
\hline Health examination & 5 & Financial management & 3 \\
\hline Emergency Department & 5 & Human resource management & 2 \\
\hline Ward management & 4 & Medical service quality & 1 \\
\hline Radiology Department & 4 & Medical insurance management & 1 \\
\hline ICU (Intensive Care Unit) & 2 & Propaganda work & 1 \\
\hline Department of Obsterics & 2 & Medical safety management & 1 \\
\hline Department of Respiratory & 2 & Identity management & 1 \\
\hline Digestive endoscopy center & 1 & Hospital culture & 1 \\
\hline Pediatrics Department & 1 & health care for cadres & 1 \\
\hline Pre hospital emergency management & 1 & Medical Waste Management & 1 \\
\hline Anesthesia recovery room & 1 & & \\
\hline Department of general surgery & 1 & & \\
\hline Blood Transfusion Department & 1 & & \\
\hline Dental Department & 1 & & \\
\hline Cardiac surgery & 1 & & \\
\hline Department of Orthogedics & 1 & & \\
\hline Department of Radiotherapy & 1 & & \\
\hline Department of Gynaecology & 1 & & \\
\hline Department of Neurology & 1 & & \\
\hline Department of Neurosurgery & 1 & & \\
\hline
\end{tabular}

Lean (see Fig. 5). All the outcomes are positive; unsurprisingly, failures are not reported. Reported outcomes of the 127 hospitals are supported by specific data.

Among the 124 hospitals that provided information the outcomes are shown in Fig. 5, 78 improved medical quality control; 60 claimed positive results in the indicators relating to improved work processes and decreased waiting times; 48 hospitals improved patient satisfaction; 39 hospitals improved cost effectiveness and 34 hospitals claimed that they have improved staff satisfaction and enthusiasm; 26 hospitals have improved work efficiency; 21 hospitals have achieved an improvement in management and 16 claimed that communication and teamwork among employees have improved; 15 hospitals mentioned improved safety. It is worth noting that there are 13 hospitals claiming that they have achieved an increase in workload and economic benefits, and 12 hospitals have reduced their inventories. As Chinese public hospitals rely mainly on their own income they are largely driven by economic interest.
Less commonly they reported improved competitiveness, worker empowerment, improved hospital reputation and improved research and teaching.

These findings show that the main focus of the hospitals on the application of lean is to optimize processes to improve operational efficiency and not to meet the needs of patients. For example, "As the hospital business continues to rise, for example, the hospital outpatients increased from 665,000 person-time in 2006 to $1,052,000$ person-time in 2009. However, over the same period, the number of hospital staff only increased from 1020 to 1126 ....we realized that we must improve our work efficiency and reduce the occurrence of errors" [45]. The goal of another hospital to apply lean is to "reduce operating costs, improve efficiency" [53]. Similarly, the purpose of a hospital in optimizing operating theater procedure is to reduce the waste of human resources and material resources, improve work efficiency and staff satisfaction degree [56]. 
Table 2 The frequency of methods or tools of lean used in Chinese hospitals

\begin{tabular}{|c|c|c|c|c|c|}
\hline Rank & Methods or Tools & № & Rank & Methods or Tools & № \\
\hline $1 s t$ & 5S (Sort, Set in order, Shine, Standardize, Sustain) related & 31 & 17th & Kanban & 2 \\
\hline 2nd & Value Stream Map & 24 & 17 th & Pareto analysis & 2 \\
\hline 2nd & Fishbone Diagram & 24 & 23th & Just In Time & 1 \\
\hline 4 th & Six Sigma & 19 & 23th & Push & 1 \\
\hline 5 th & Work-out & 16 & 23th & Transaction improvement & 1 \\
\hline 6th & Visual management & 12 & 23th & Zero inventory & 1 \\
\hline 7th & DMAIC (Define, Measure, Analyze, Improve, Control) & 11 & 23th & Jidoka & 1 \\
\hline 8th & Brainstorming & 10 & 23th & Water spider & 1 \\
\hline 8th & PDCA (Plan, Do, Check, Act) & 10 & 23th & Takt Time and One piece flow & 1 \\
\hline 10th & Spaghetti Chart & 8 & 23th & Scenario simulation & 1 \\
\hline 10th & QCC (Quality Control Circles) & 8 & 23th & Monte Carlo simulation & 1 \\
\hline 12th & SOP (Standard Operation Procedure) & 7 & 23th & SIPOC (Supplier, Input, Process, Output, Customer) & 1 \\
\hline 13th & Pull System & 5 & 23th & Three-point estimation & 1 \\
\hline 14th & ECRS (Seliminate, combine, rearrange, simplfify) & 3 & 23th & RPN (Risk Priority Number) & 1 \\
\hline 14th & Standard Work & 3 & 23th & CTQ (Critical-To-Quality) & 1 \\
\hline 14th & Flow Chart & 3 & 23th & Control influence matrix & 1 \\
\hline 17th & Location management & 2 & 23th & Failure Mode and Effect Analysis & 1 \\
\hline 17th & 5WIH (Who, When, Where, What, Why, How) & 2 & 23th & GRPI (Goal, Rote, Process, Interpersonal relationship) & 1 \\
\hline 17th & Pokayake & 2 & 23th & Root cause analysis & 1 \\
\hline 17th & $80 / 20$ principle & 2 & & & \\
\hline
\end{tabular}

\section{Inter-relations of technical, social and organizational dimensions in the lean implementation process}

Twenty six hospitals mentioned the importance of training in lean implementation Twenty two hospitals believed that cultural support is an important factor in the successful implementation of lean. This might include staff involvement as noted by 7 hospitals and support and empowerment of the top leaders noted by 6. Three hospitals referred to the need to combine incentives and lean implementation. Cross sector cooperation was also mentioned.

Twenty two articles mentioned the relationship between lean and culture. Lean management is considered as an idea, an attitude, and a reflection of culture [53]. The hospital lean culture is considered as an important link in the hospital lean management chain [57]. The deepening of health care reform and the intensifying competition in the medical service market put forward higher requirements to the hospital management, therefore, "hospital management will need to learn some advanced business philosophy and technology to improve the level of management" [58], lean management has become the choice of some hospital administrators [58]. However, because of the application of new management concepts and methods, it is necessary to change the existing habits, inevitably bringing about conflicts with the original culture. Therefore, Christopher, et al. [59] pointed out that before the lean technology is widely applied, there are many cultural barriers that must be overcome, including transferring a manufacturing concept into the medical sector. Geng et al. [58] argues that the cultural change brought about by the implementation of lean is not a cultural alternative to another culture, but a fusion of innovation based on the original culture. They emphasized that the main reason for the hospital to choose lean is that its inherent characteristics of hospital culture accord with the lean management concept [58].

\section{Discussion}

Public hospitals have had to pay more attention to justify the use of limited resources and improve operational efficiency; these appear to have resulted in the demand for Lean. The evidence for this is that the most important outcomes are the increase in workload or economic benefits.

Western literature suggests that consultants, due to the lack of medical background, are not easily accepted by medical personnel in lean implementations [60]. In China, hospitals tend to use consultants for lean which can suggest greater acceptance as well as promotion of their services. This differs from previous studies that showed that consultants did not play an important role in the diffusion of the balanced scorecard in Chinese 


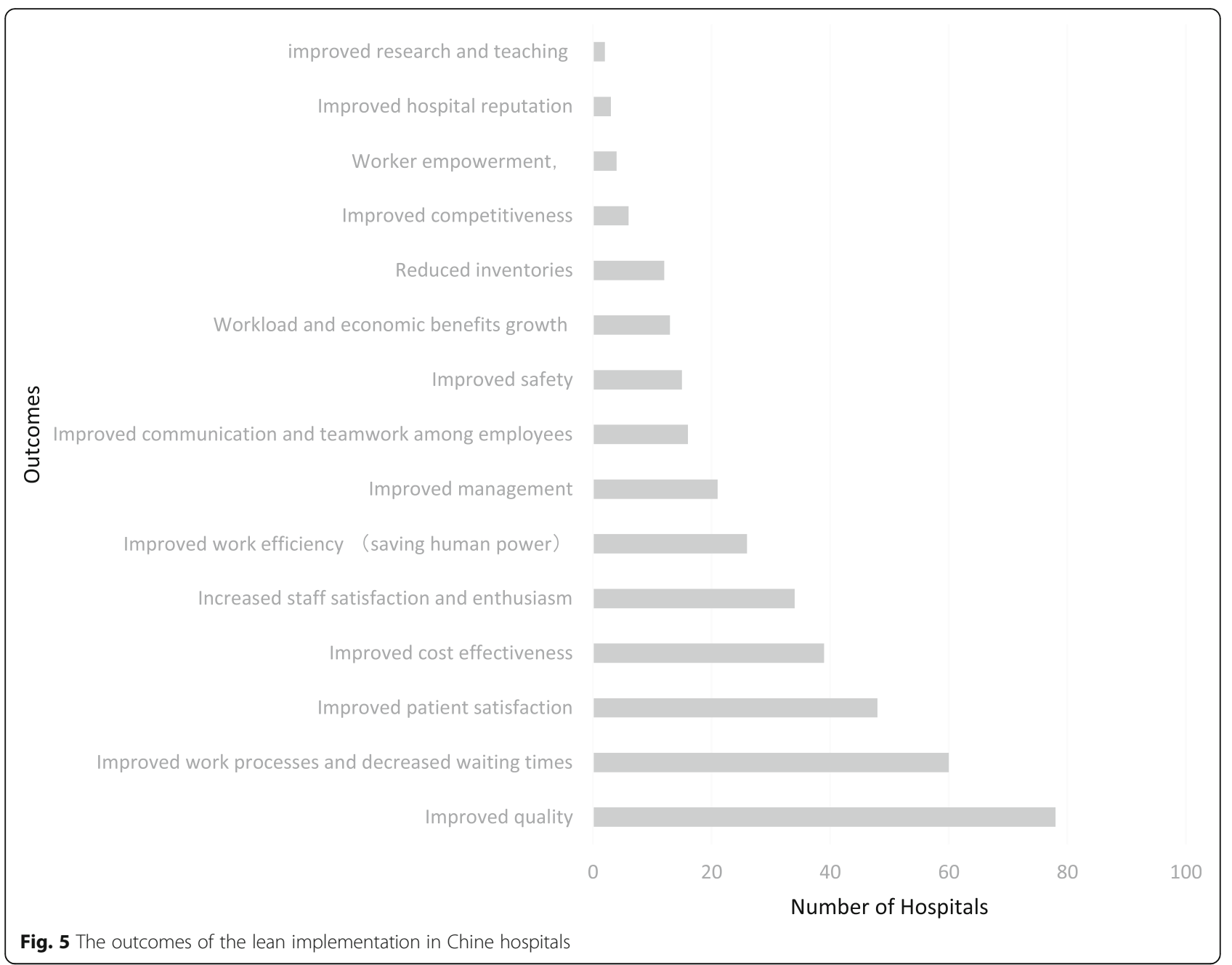

hospitals [61]. This may because the technical methods of lean are from manufacturing industry which are not easily understood by medical professionals.

Most of the 74 hospitals have more than 500 beds. Previous studies have indicated that larger organizations are more likely to use specialized and sophisticated management control systems [62]. As larger organizations have more decentralized organizational structures and more specialized tasks and complicated processes, more advanced management control systems are required by these larger organizations [62]. Larger hospitals have more patients, so there is more demand for optimizing the process. They also have more resources to invest in processes such as lean. But as the knowledge of lean grows, more small hospitals have begun to use lean to improve their management.

However, in healthcare, the lack of a standard definition of the customer value of lean $[15,63]$ will impact the outcomes of lean applications. The findings presented in this paper suggest that lean in Chinese hospitals is mainly used to eliminate process waste and improve the efficiency of the service for patients, which seem to be inconsistent with the patient as the centre of the lean concept. But there was no evidence of using it for over-treatment, the great waste of medical resources. This is mainly due to the heavy financial pressure faced by Chinese hospitals. In this study, 26 hospitals claimed that they have achieved improved cost effectiveness, but there are no hospitals who claim that they have successfully reduced the expenditures of patient care. Patient satisfaction increased mainly because of reduced waiting time. One of the reasons is that health expenditure control is also a difficult point for hospitals around the world, and another reason is that if the hospital reduces the expenditures of patient care, the hospital's revenue would be possibly reduced as well, so they prefer to reduce operational cost to maximize their operational benefits. Hence, it is not difficult to understand that patients are not the real focus in the application of lean in most Chinese hospitals.

In comparison with Western hospitals, Chinese hospitals focus more on fields with a high flow pressure 
such as outpatient, pharmacy, and other related units. All the Chinese hospitals have their own pharmacy, and have more outpatient visits than western hospitals.

Balle and Regnier [64] argue that lean should be considered as a complex thinking system; a philosophy, not just a combination of tools. Some authors thought that applying lean as a project will have a negative impact on the achievement of continuous improvement $[15,65]$. We found only 6 hospitals have used a systemic way to implement lean in their hospitals, most hospitals applied lean as a project. But the results of this study demonstrate that the application of the project can be perceived to achieve continuous improvement. For example, 35 hospitals believe that the implementation of lean projects can achieve continuous improvement.

Theoretically, a systematic application of lean can achieve better results. But in healthcare, medical personnel's professional culture requires them to see the evidence [66] because doctors who have a strong tradition in evidence-based care are willing to accept the change based on good evidence [66]. Therefore, the single project implementation has a positive significance as it can provide a quick effect and promote the application in the whole system. Although its effect is limited compared with the systematic application, it can effectively promote lean in healthcare, and achieve sustainable results. Therefore, partial application is not a limitation. It is an inevitable path for the development of lean in the healthcare industry. Even a hospital that has systematically applied lean for 3 years has not fully implemented lean into every sector [45], which illustrates the implementation of lean is a long-term work. As Radnor et al. noted that the evolution of lean in healthcare will be similar as in manufacturing industry, "from shop-floor based tools, to a process view, and ultimately, to a holistic understanding of pathways across organisations if the benefits of Lean are to be fully realised" [15].

Although the study found that 39 lean tools had been used, most of the tools were mastered by a very small number of hospitals. Lack of lean knowledge is still an important issue in Chinese hospitals, which will directly affect its promotion. Due to the holistic and long-term nature of lean implementation, and the lack of knowledge and technology, the emergence of fake lean $[67,68]$ is not surprising.

With the enhancement of national health care reform, the implementation of public hospital reform and the promotion of market competition, Chinese hospital is faced with the urgent need to improve the management level quickly, but they lack the scientific method to solve the specific management problems, so the application of foreign advanced management tool such as lean has become a trend.

In addition, because of the impact of professional culture, medical staff are willing to accept a new method after they have seen the evidence of success. Therefore, it is not surprising that lean applications in Chinese hospitals are mostly localized rather than idealized whole hospital applications.

For a long time, due to the lack of the pressure of market competition, Chinese hospitals, especially public hospitals, rely on vague experience based management based on self-discipline culture. When this kind of fuzzy experience management based on self-discipline culture needs to be changed to scientific and specific lean management through standardization, the change of people's concept is very important. The change of concept requires a long process, which is difficult to be achieved through the implementation of a single lean project. In the future, it will be an inevitable trend to realize the integration of the external lean theory and traditional Chinese culture through the systematic and strategic lean implementation so as to achieve sustainable improvement in line with the lean methodlogy.

\section{Conclusions}

The findings in this paper show that the broader context has an important influence on the application and the application of lean in Chinese hospitals. The application of lean in Chinese hospitals showed a rapid upward trend, which was mainly used in the fields of outpatient services, operating room, pharmacy, logistics and so on. The main body of the application of lean is in large hospitals with more than 500 beds. With the further popularization of lean, more and more small hospitals have joined lean applications.

Most hospitals applied lean as a project. The trajectory is that hospitals are using lean as a systemic path and beginning to emphasize the relevance of lean and strategy. They still lack sufficient knowledge, which is the factor that affects the promotion of lean in Chinese hospitals. Consultants' participation played an important role in the popularization of lean tools and knowledge. Although lean management emphasizes the customer as the center to achieve improvement, the main effect indicates that lean was mainly used to improve the operating efficiency and reduce operating costs in Chinese hospitals. Patient spending and patient safety were not paid enough attention which is related to the operating pressures of Chinese hospitals.

In reviewing the publications, this paper firstly provides a general picture of the lean in Chinese Hospitals. The reflections on the present level of practice of the lean are useful for both academics and practitioners. 
The outcome of this study will be of significance for the practices of the BSC in hospitals.

In this study, we used a literature search to find out which hospitals had applied lean. This method has limitations, as implementations viewed as unsuccessful are not likely to be written up and published. And the analysis was limited by using information from papers which sometimes did not go into great detail, although we chose to do a small sample size on-site interviews. In the future, based on these findings in this study, there is an opportunity to conduct a survey of a larger scale to include all Provinces in China to get a better understanding on the lean application issues in Chinese hospitals.

\section{Endnote}

${ }^{1}$ One hospital did not provide specific information on the lean application.

\section{Abbreviations}

CQVIP: Chongqing VIP Information Co., Ltd; CNKI: Chinese National Knowledge Infrastructure; CTQ: Critical-To-Quality; DMAIC: Define, measure, analyze, improve, control; DRGs: Diagnosis related disease groups;

ECRS: Seliminate, combine, rearrange, simplfify; GE: General Electric Company; GRPI: Goal, rote, process, interpersonal relationship; ICU: Intensive care unit; PDCA: Plan, do, check, act; QCC: Quality control cycle; 5S: Sort, set in order, shine, standardize, sustain; 5WIH: Who, When, Where, What, Why, How; 6S: Sort, set in order, shine, standardize sustain, safety; 8S: Sort, set in order, shine, standardize sustain, safety, save, study; SIPOC: Supplier, Input, Process, Output, Customer; SOP: Standard operation procedure; RPN: Risk priority number

\section{Acknowledgements}

Not applicable.

\section{Funding}

Not applicable.

\section{Availability of data and materials}

Not applicable.

\section{Authors' contributions}

TG and BG collaborated in drafting the study design. TG conducted the data collection and performed the analysis and interpretation of data. TG and BG drafted the manuscript. BG contributed to the theoretical and conceptual focus of the study. All authors read and approved the final manuscript.

\section{Ethics approval and consent to participate}

The need for ethics approval of this study and informed consent, written or verbal, was obtained from all participants are deemed unnecessary according to national regulations --"The Reguation of Ethical Reviews of Biomedical Research Involving Human Subjects". National Health and Family Planning Commission of the People's Republic of China (NHFPC). The Reguation of Ethical Reviews of Biomedical Research Involving Human Subjects;2016.

\section{Consent for publication}

Not applicable.

\section{Competing interests}

The authors declare that they have no competing interests.

\section{Publisher's Note}

Springer Nature remains neutral with regard to jurisdictional claims in published maps and institutional affiliations.

\section{Author details}

${ }^{1}$ Planning and Finance Department, Jinan Central Hospital Affiliated with Shandong University, Jinan 250013, China. ${ }^{2}$ University of South Australia, Adelaide, Australia. ${ }^{3}$ Australian Centre for Asian Business, University of South Australia, Adelaide, Australia.

Received: 27 February 2018 Accepted: 15 January 2019

Published online: 24 January 2019

\section{References}

1. Womak J, Jones D. Lean thinking. New York: Simon and Shuster; 1996.

2. Houchens N, Kim CS. The Application of Lean in the Healthcare Sector: Theory and Practical Examples. In: Wickramasinghe N, Al-Hakim L, Gonzalez C, Tan J, editors. Lean Thinking for Healthcare. New York Heidelberg Dordrecht London: Springer; 2013. p. 43-54.

3. Maijala R, Eloranta S, Reunanen T, Ikonen TS. Successful implementation of lean as a managerial principle in health care: a conceptual analysis from systematic literature review. Int J Technol Assess Health Care. 2018;34(2):134-46.

4. Su Y, Soar J, Shen N, Al-Hakim L. Adapted Lean Thinking for Healthcare Services: An Empirical Study in the Traditional Chinese Hospital. In: Wickramasinghe N, Al-Hakim L, Gonzalez C, Tan J, editors. Lean Thinking for Healthcare. New York Heidelberg Dordrecht London: Springer; 2013. p. $115-42$.

5. Zwicker M, Seitz J, Wickramasinghe N. Identifying Critical Issues for Developing Successful e-Health Solutions. In: Wickramasinghe N, Al-Hakim L, Gonzalez C, Tan J, editors. Lean Thinking for Healthcare. New York Heidelberg Dordrecht London: Springer; 2013. p. 207-24.

6. Burgess NJ. Evaluating Lean in Healthcare. In: University of Warwick, Warwick Business School; 2012.

7. Krafcik JF. Triumph of the lean production system. Sloan Manag Rev. 1988; 30(1):1566-74.

8. Deara A, Deara M, Bamber C, Elezi E. A comparative analysis of lean implementations in NHS England hospitals. International Journal of Lean Enterprise Research. 2018;2(3):218-39.

9. Cusumano MA. Manufacturing Innovation: Lessons from the Japanese Auto Industry Sloan Management Review. 1988;30(1, Fall):29-39.

10. Holweg M. The genealogy of lean production. J Oper Manag. 2007;25(2):420-37.

11. Cresswell K, Sheikh A. Organizational issues in the implementation and adoption of health information technology innovations: an interpretative review. Int J Med Inform. 2013;82(5):73-86.

12. D'Andreamatteo A, lanni L, Lega F, Sargiacomo M. Lean in healthcare: a comprehensive review. Health Policy. 2015; https://doi.org/10.1016/j. healthpol.2015.02.002.

13. Joosten T, Bongers I, Janssen R. Application of lean thinking to health care: issues and observations. International Journal for Quality in Health Care Journal of the International Society for Quality in Health Care. 2009;21(5):341-7.

14. Mazzocato $P$, Savage $C$, Brommels $M$, Aronsson $H$, Thor J. Lean thinking in healthcare: a realist review of the literature. Quality and Safety in Health Care. 2010;19(5):376-82.

15. Radnor ZJ, Holweg M, Waring J. Lean in healthcare: the unfilled promise? Soc Sci Med. 2012;74(3):364-71.

16. Andersen $H$, Røvik KA, Ingebrigtsen T. Lean thinking in hospitals: is there a cure for the absence of evidence? A systematic review of reviews. BMJ Open. 2014;4(1):e003873.

17. Burgess N, Radnor Z. Evaluating lean in healthcare. International Journal of Health Care Quality Assurance. 2013;26(3):220-35.

18. Dahlgaard JJ, Pettersen J, Dahlgaard-Park SM. Quality and lean health care: a system for assessing and improving the health of healthcare organisations. Total Qual Manag Bus Excell. 2011;22(6):673-89.

19. Costa LBM, Godinho Filho M. Lean healthcare: review, classification and analysis of literature. Production Planning \& Control. 2016;27(10):823-36.

20. Brännmark $M$, Lindskog $P$, Halvarsson A. Patient quality effects from lean healthcare: an empirical investigation. In: NES2012 proceedings.: ergonomics for sustainability and growth, Stockholm: KTH Royal Institute of Technology; 2012.

21. Shazali NA, Habidin NF, Ali N, Khaidir NA, Jamaludin NH. Lean healthcare practice and healthcare performance in Malaysian healthcare industry. International Journal of Scientific and Research Publications. 2013;3(1):1-5. 
22. Al-Balushi S, et al. Readiness factors for lean implementation in healthcare settings-a literature review. Journal of health organization and management. 2014;28(2):135-53.

23. Poksinska B. The current state of lean implementation in health care: literature review. Quality Management in Health Care. 2010;19(4):319-29.

24. Holden RJ. Lean thinking in emergency departments: a critical review. Ann Emerg Med. 2011;57(3):265-78.

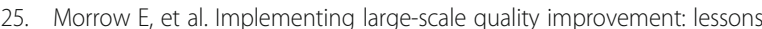
from the productive Ward:releasing time to care. International Journal of Health Care Quality Assurance. 2012;25(4):237-53.

26. Niemeijer, G., et al.. Generic project definitions for improvement of health care deliv-ery: a case-based approach Quality Management in Health Care. 2011;: 20(2): 152-164.

27. Jin M, Switzer M, Agirbas G. Six Sigma and Lean in healthcare logistics centre design and operation: a case at North Mississippi Health Services International. Journal of Six Sigma and Competitive Advantage. 2008;4(3):270-88.

28. National Health and Family Planning Commission of the People's Repubic of China. China Health and Family Planning Statistics Yearbook 2016. Beijing: Peking Union Medical College press; 2016.

29. Deng Y. Focus on patient and improve healthcare quality - overview of hospital management year working conference. Chinese Hospitals. 2005;9(5):4-6.

30. National Development and Reform Commission. (2009). Health care reform plan 2009 [online]. Available: http://www.gov.cn/jrzg/2009-04/06/content_ 1278721.htm. Accessed 2 Jan 2019

31. Wang $\mathrm{H}$. A dilemma of Chinese healthcare reform: how to re-define government roles? China Econ Rev. 2009;20(4):598-604

32. Dong K. Medical insurance system evolution in China. China Econ Rev. 2009;20(4):591-7.

33. General Office of the State Council. Guidance of the General Office of the State Council on the comprehensive reform of urban public hospitals. 2015. [Online]. Available: http://www.gov.cn/zhengce/content/2015-05/17/ content_9776.htm [Accessed 1 Sept 2015].

34. Liu XZ, Liu YL, Chen NS. The Chinese experience of hospital Price regulation. Health Policy Plan. 2000;15(2):157-63.

35. Wang S. The tradition of Confucian moral cultivation and the cultivation of modern personality. Journal of Chongqing University of Science and Technology (Social Sciences Edition). 2009;7:157-8.

36. Hsiao W. The Chinese health care system: lessons for other nations. Soc Sci Med. 1995;41(8):1047-55.

37. Wong V, Chiu S. Health-care reforms in the People's republic of China. Journal of Management in Medicine. 1998;12(4/5):270-86.

38. Liu X, Mills A. The effect of performance-related pay of hospital doctors on hospital behaviour: A case study from Shandong, China. Human Resources for Health. 2005:3:11.

39. Dib HH, Hong SY, Bin Z, Hongliang S. Health care costs in China: need for intervention. J Health Manag. 2007;9(1):85-103.

40. Braam G, Benders J, Heusinkveld S. The balanced scorecard in the Netherlands. Journal of Organization Change Management. 2007;20(6):866-79.

41. Lin JK, Zhao MJ. A trial on the hospital practice of "consummate service". Chinese Journal of Hospital Administration. 1997;6:363-4.

42. Ren Z. To Promote High Quality Nursing Services with Lean Management. Journal of Capital Medical University (Social Science Edition). 2013;4:20-3.

43. Yi LH, Zhao Y, Hu MM, Xing M. Delicacy management chain and its role in improvement of hospital management and service. Chinese Journal of Hospital Administration. 2014;30(3):174-7.

44. Luo J, Xu DG, Luo F, Jiang F, Shang XK, Tu ZL, Feng XM. Practice and experience of applying lean management in our hospital. Chinese Hospital Management. 2011;31(9):22-3.

45. Zhao YM, Zhang WY, Chen X, Li FM, Hu RY, Xu FX, Ma DM, Zhang JF. Exploration of improved hospital creation by all workers with the introduction of Toyota production system. Modern Hospital Management. 2014;12(2):41-4.

46. Liu H, Li YM. An explore of innovation leading propaganda work to boost the construction of lean hospital. Capital Medicine. 2013:6:14-6.

47. Ye CQ, Zhao DH, Qu HY, Zhang LP, Hu Z, Li QY. Practice and thinking of application of lean in the physical examination center. Journal of Military Surgeon in Southwest China. 2015;17(3):352-3.

48. Fan $\mathrm{KH}$. Experience of the implementation lean Management in Drugstores in our hospital. China Pharmacy. 2011;22(25):2355-7.

49. Xia ZM. The effect of lean management on the punctual start rate in operating room. Chinese Journal of Rural Medicine. 2015;22(4):102-3.
50. Xiang YJ, Li LZ. Optimizing outpatient procedure by lean management. China Hospital CEO. 2012;17:76-7.

51. Wang XL, Wang Q, Li HC. Attempts to lean management in optimizing the nursing work process. Hospital Directors' Forum. 2012;3:54-6.

52. Liu M, Zhao DH, Qu HY, Li QY. Use lean management to improve the efficiency of hospital financial management. For all Health (Academic Edition). 2014;8(2):383

53. Zhou YJ, Zhu ZM. Promotion of lean management of hospital human resource by the thinking of people oriented. China Medical Herald. 2011;35:140-2.

54. Zeng DM, Zhang ZJ. Build a new hospital culture with lean management as the guide. Economist. 2012;10:282-3.

55. Lin H, Wang YH, Qu BX, Xia P. Applying lean management in process optimization of outpatient pharmacy. Chinese Journal of Hospital Administration. 2009;25(2):83-4.

56. Zhang J, Tan JM. Optimization of a surgery scheduling system based on lean management. J Nurs Sci. 2014;29(10):45-7.

57. Li Y, Hu MM. On hospital culture construction from the perspective of lean management. Value Engineering. 2014;31:200-1.

58. Geng RW, Lin JX, Zhu H, Wang JY. Introduction of lean management and innovation of hospital culture. Chinese Journal of Hospital Administrati. 2008;24(5):289-91,97.

59. Christopher SK, David AS, Jeanne MK, John EB, Yuan J. Inspirations of Toyota's perfection management on the medical industry. Chinese Journal of Hospital Administration. 2009;25(2):77-80.

60. Fillingham D. Can lean saves lives? Leadersh Health Serv. 2007;20(4):231-41.

61. Gao T. Analysis on the diffusion of the balanced scorecard in Chinese hospitals based on PMI method. Chinese Hospitals. 2015;2:33-4.

62. Speckbacher G, Bischof J, Pefeiffer T. A descriptive analysis on the implementation of balanced scorecard in German-speaking countries. Manag Account Res. 2003;14(4):361-87.

63. Young TP, Mcclean SI. A critical look at lean thinking in healthcare. Quality \& Safety in Health Care. 2008;17(5):382-6.

64. Ballé M, Régnier A. Lean as a learning system in a hospital ward. Leadersh Health Serv. 2007;20(1):33-41.

65. Radnor Z, Boaden R. Editorial: Lean in public services-panacea or paradox? Public Money \& Management. 2008;28(1):3-7.

66. Goossens A, Bossuyt PMM, De Haan RJ. Physicians and nurses focus on different aspects of guidelines when deciding whether to adopt them: an application of conjoint analysis. Med Decis Mak. 2008;28(1):138-45.

67. Emiliani B. Real. In: Lean: Understanding the lean management system. The Center for Lean Business Management. Wethersfield, CT: LLC; 2007.

68. White M, Wells J, Butterworth T. Leadership, a key element of quality improvement in healthcare. Results from a literature review of "lean healthcare" and the productive Ward: releasing time to care initiative. The International Journal of Leadership in Public Services. 2013;9(3/4):90-108.

Ready to submit your research? Choose BMC and benefit from:

- fast, convenient online submission

- thorough peer review by experienced researchers in your field

- rapid publication on acceptance

- support for research data, including large and complex data types

- gold Open Access which fosters wider collaboration and increased citations

- maximum visibility for your research: over $100 \mathrm{M}$ website views per year

At BMC, research is always in progress.

Learn more biomedcentral.com/submissions 